\title{
Quantification of Residual Stresses in External Attachment Welding Applications - Part II: Effect of Preheating and Clamping Conditions
}

\author{
The study investigates the effects of clamping and preheating on \\ residual stress extension behaviors in external attachment welds
}

BY R. ALHAJI AND S. LIU

\begin{abstract}
There has been uncertainty whether postweld heat treatment (PWHT) should be required for external attachment welding applications where stress corrosion cracking (SCC) is a possibility. An industrial criterion established by NACE SP0472, paragraph 3.6.1, indicates PWHT is not required if tensile residual stresses do not extend through the entire wall thickness. To investigate this problem, a finite-element analysis (FEA) software, Sysweld ${ }^{\mathrm{TM}}$, was utilized to predict the extent and level of residual stresses of such welds through the thickness of the pressure vessel shell to study the influence of clamping and preheating. Experimental validations following AWS A9.5 standard were performed. The study used ASTM-516 grade 70 steel plates of $6.3,12.7$, and $19 \mathrm{~mm}$ thicknesses. The effects of rigid clamping and preheating from $95^{\circ}$ to $135^{\circ} \mathrm{C}$ on the residual stress distributions following the thickness direction were studied. The clamping condition results showed residual stresses were increased consistently in the weld metal and heat-affected zone (HAZ) at significant levels observed at $6.3 \mathrm{~mm}$ thickness and minimum levels at $19 \mathrm{~mm}$. Such effect was attributed to lower distortion displacement at higher pressure vessel thicknesses compared to the higher distortions at lower thicknesses. Due to thermal strain reduction and insignificant changes of metallurgical phase amounts, the residual stresses in the thickness direction were slightly decreased due to preheating. When welded with preheating or clamping, maximum tensile residual stresses exceeding $80 \%$ of yield strength existed in the bottom surface of the 6.3-mm-thick plates but only 19 to $30 \%$ yield strength in the 19-mm-thick plates. The conclusions indicate that 6.3-mm-thickness applications demand PWHT whereas $19 \mathrm{~mm}$ or greater thicknesses are potentially safe depending on the loading conditions.
\end{abstract}

\section{KEYWORDS}

- Finite-Element Analysis • Arc Welding • Residual Stress • Preheating - Hole-Drilling Strain Gauge $\bullet$ Clamping

\section{Introduction}

Fusion welding conditions, such as preheating and interpass temperature, clamping, and weld bead sequencing, have been investigated and identified to affect the residual stress distribution in welded structures (Refs. 1-10). For carbon-manganese and low-alloy steels, preheating has been well identified to reduce the susceptibility to cold hydrogen-assisted cracking (HAC) as well as reducing, to a limited extent, the weld metal and heat-affected zone (HAZ) thermal strains during welding inherent thermal cycles. The reduction of thermal strains thereby reduces the local stresses in the weld metal and HAZ. Due to constraining the distortion displacements, clamping has been identified to increase the tensile residual stress value in the weld metal and HAZ within welded structures. The typical fusion weld metal and HAZ residual stresses are tensile and usually significant reaching the local yield strength. These stresses, therefore, have been identified to increase the tendency of brittle fracture, fatigue failures, and environmental stress-corrosion cracking $(\mathrm{SCC})$.

Along with many researchers, Teng et al. investigated the effect of transverse clamping and preheating on the residual stress distribution in steel plate single-pass autogenous butt joints using ANSYS finite-element analysis (FEA) modeling (Ref. 6). As shown in Fig. 1A, the effect of the transverse mechanical clamping at plate edges showed an overall increase of the transverse residual stress profile by shifting the profile up, through following the longitudinal axis of the weldment. The longitudinal axis represents the welding path line according to the sample geometry followed by Teng et al. A beneficial effect of preheating by reducing the weld metal thermal strains and stresses can be observed in Fig. 1B. For instance, at $200^{\circ} \mathrm{C}$ preheating, the transverse tensile residual stress peak was reduced by $30 \%$ and the transverse compressive residual stress values were reduced, compared to the unpreheated condition. Adedayo and Adeyemi also investigated the effect of preheating on the residual stress distribution in a 6-mm-thick arc welded mild steel plate (Ref. 7). A reduction range of 50 to $75 \%$ in the weld metal peak longitudinal residual stresses compared to the un-preheated condition was observed after measuring the weld metal residual stresses.

Residual stress mitigation methods 


\section{A}

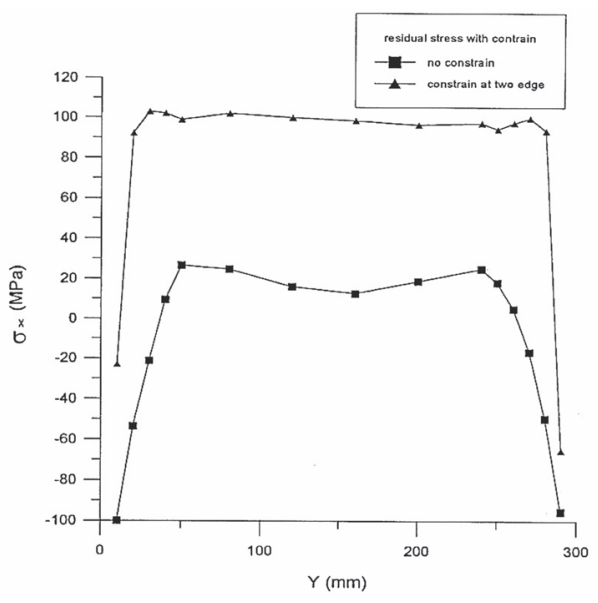

\section{B}

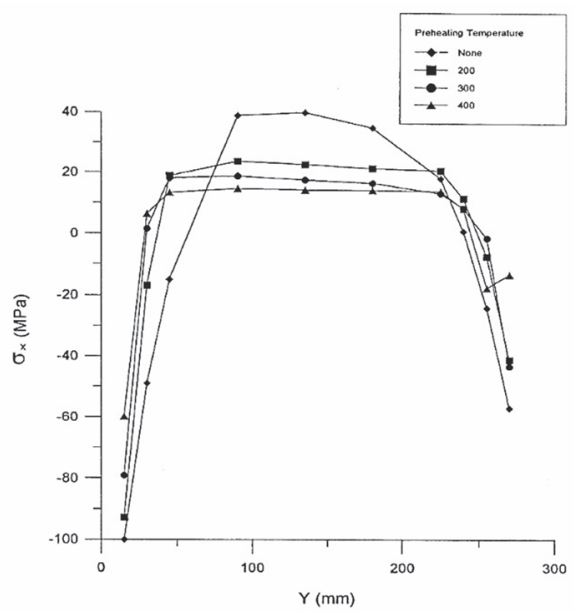

Fig. 1 - Transverse residual stress distributions along the $y$-axis (welding path): A - Clamped and unclamped conditions; B - unclamped and preheated at different temperatures (Ref. 6).

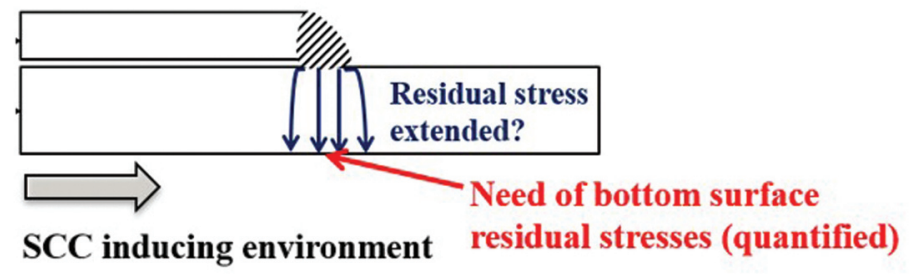

Fig. 2 - Schematic example illustrating an external attachment nonpressure retaining weld applied to pressure vessels and piping.

such as shot peening, high frequency impact treatment, and postweld heat treatment (PWHT) have been investigated in the literature and were identified to relieve appreciable amounts of residual stresses (Refs. 11-15). PWHT in the oil, gas, and petrochemical industries has mostly been utilized to relieve the residual stresses of weldments used in SCC-inducing environments. According to equipment fabrication codes, such as ASME Boiler and Pressure Vessel Code (BPVC), Section VIII; ASME B31.3, Process Piping Guide; and API 650, Welded Tanks for Oil Storage, such weldments shall receive PWHT because the weld metal and HAZ, which typically experience high tensile residual stresses, are directly exposed to the SCC environments.

However, such criterion has not been clearly recognized for other types of weldments in which a weld metal and $\mathrm{HAZ}$ are not directly exposed to the SCC environment. Figure 2 schematically illustrates an example of an external attachment nonpressure retaining weld joining a reinforcing pad or sleeve to a pressure vessel shell, nozzle, or piping.
In such application, the high residual stresses in the weld metal and HAZ may extend to the bottom surface of a pressure vessel or pipe wall where environmental SCC is in direct exposure. This situation has led to uncertainty on whether PWHT shall be applied in such special types of applications. A previous work is being published to demonstrate the residual stress extension behavior from the weld metal to the bottom surface of such an application and quantify the residual stress levels extended to the bottom surface (Ref. 17). This paper aims to extend the study by investigating the effects of clamping and preheating on residual stress extension behaviors in external attachment welds. Studying such effects will similarly help determine the PWHT requirement and draw conclusions on the clamped and preheated external attachment welding application.

\section{Finite-Element Analysis Modeling Procedures}

To study the effects of clamping

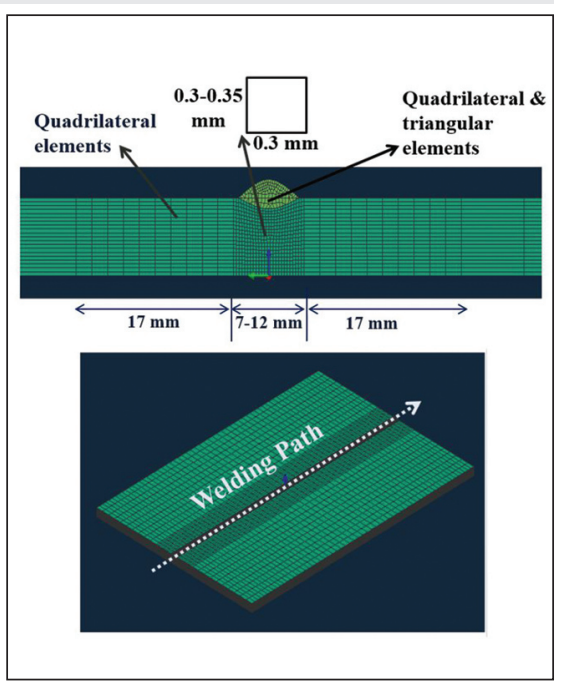

Fig. 3 - FEA model meshing details illustrated at the front view plane and isometric view.

and preheating on residual stress distributions, finite-element analysis (FEA) modeling, utilizing the Sysweld ${ }^{\mathrm{TM}}$ software, was performed. The same single-pass bead-on-plate weldments studied in Part I of this research were created to enable a detailed relevant comparison with the unpreheated and unclamped welding condition (Ref. 17). The meshing details of the bead-on-plate weldments are shown in Fig. 3. The base metal and HAZ regions were mostly composed of quadrilateral 3D elements while both triangular and quadrilateral $3 \mathrm{D}$ elements were created in the weld metal region, with no interior angles less than $20^{\circ} \mathrm{C}$. Underneath the weld metal, fine-scale through-thickness 3D 

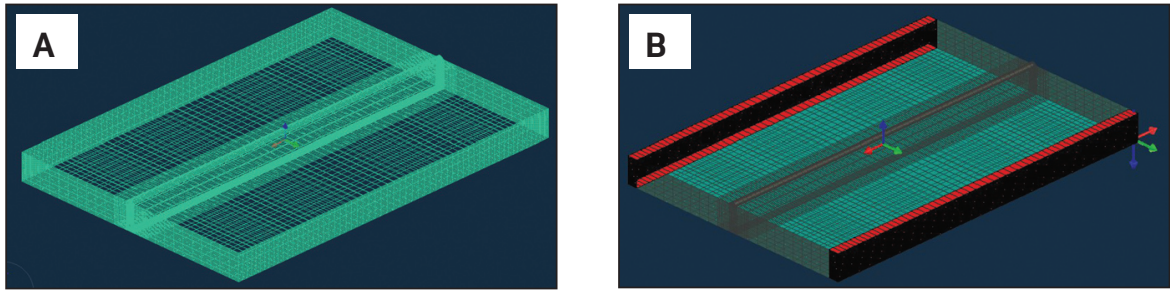

Fig. 4-A - 2D surface elements for preheating and cooling boundary condition; $B$ $-2 D$ surface elements (highlighted red) representing a $3 D$ rigid clamping.

Table 1-Preheating Temperatures Selected as a Function of Base Plate Thickness

Base Plate Thickness (mm)

6.3

12.7

19
Preheating Temperature $\left({ }^{\circ} \mathrm{C}\right)$

95

117

135 elements were created to accurately and incrementally study the local residual stress extension behavior in the through-thickness direction from the weld metal bottom weld interface to the bottom surface. The FEA used Goldak's double-ellipsoid heat source model, which is applicable to arc welding processes. The heat source parameters were iteratively calibrated until the experimentally measured fusion zone morphology was reached.

To study the effect of preheating, 2D surface elements, illustrated in Fig. $4 \mathrm{~A}$, were created at all model exterior surfaces where both preheating and free air cooling at ambient temperature of $20^{\circ} \mathrm{C}$ were imposed. The preheating temperatures studied are detailed in Table 1 and were selected by following the minimum necessary preheating temperature criteria developed by Yurioka et al. (Ref. 18). These criteria were established to avoid cold $\mathrm{HAC}$ in carbon and low-alloy steels. In the case of no preheating, $20^{\circ} \mathrm{C}$ was set prior to welding at the 2D surface elements. To simulate the clamping welding condition, the 2D elements highlighted in Fig. 4B were set with restricted displacements in the $\mathrm{x}, \mathrm{y}$, and $\mathrm{z}$ axes to impose a 3D rigid clamping.

The used FEA modeling computes temperature, metallurgical phases, residual stresses, and distortion transient results through the use of a material-property database that is varied as a function of temperature and transiently present metallurgical phase. In addition, the effect of phase transformation is considered in the FEA modeling through the use of con- tinuous cooling and austenitization transformation diagrams. Figures 5 and 6 illustrate some of the material properties included in the FEA modeling database of A516 Grade 70 steel (base plate) and ER-70S6 (weld metal) selected in this study, respectively.

\section{Experimental Validation Procedures}

To meet AWS A9.5, Guide for Verification and Validation in Computation Weld Mechanics (Ref. 30), experimental validations were performed at the unpreheated and unclamped conditions and their detailed results were illustrated in Part I of this study (Ref. 17). The validations included microstructural analysis, as well as temperature, residual stress, and distortion measurements. Such validations were aimed to validate the computations of the FEA modeling and the accuracy of the material-property database utilized. In the microstructural analysis, point counting was used to quantify the observed weld metal metallurgical phases by following the ASTM E56211 standard (Ref. 19).

The metallurgical phase identification followed the criteria detailed in the International Institute of Welding's (IIW) classification and terminology of microstructures in low C, lowalloy steel weld metal (Refs. 20, 21). During phase identification, distinction was made between Widmanstätten ferrite and ferrite with second phase, where Widmanstätten ferrite was agglomerated within the weld metal total weld metal ferrite. For the residual stress measurements, the hole-drilling strain gauge method was performed at the bottom surface with a setup illustrated in Fig. 7A. The residual stress measurement followed the procedures in the ASTM E837 standard (Ref. 23). The distortion profiles were measured at the bottom surface by following the transverse axis, as shown in Fig. 7B. In Fig. 7B, the longitudinal axis shown represents a projection of the weld metal centerline at the bottom surface.

In the experimental validation, single-pass bead-on-plate weldments were applied on $178 \times 254 \mathrm{~mm}$ ASTM516 Grade 70 C-Mn pressure vessel quality steel plates. This was to simulate a single bead external attachment weld, as a starting point, as elaborated in Part I. The gas metal arc welding (GMAW) process was used with the conventional GMAW C-Mn steel welding wire, ER70S-6 (1.2 mm diameter), and a shielding gas composition of $75 \% \mathrm{Ar}-25 \% \mathrm{CO}_{2}$. Different heat inputs within a range of 327 to $509 \mathrm{~J} / \mathrm{mm}$ were followed to study the effect of heat input on the weld metal microstructure and the weldment residual stress distributions. In addition, three base plate thicknesses - 6.3, 12.7 , and $19 \mathrm{~mm}$ - were studied to analyze the effect of base plate thickness on the microstructure and the residual stress distributions.

\section{Experimental Validation Results}

Figure $8 \mathrm{~A}$ and $\mathrm{B}$ shows the weld metal optical micrographs obtained at a heat input of 327 and $509 \mathrm{~J} / \mathrm{mm}$ and base plate thickness of $6.3 \mathrm{~mm}$, respectively. At $327 \mathrm{~J} / \mathrm{mm}$ heat input, the weld metal was observed to have an appreciable amount of ferrite with second phase and lath martensite in conjunction with a lower amount of grain boundary ferrite. Performing a horizontal Vickers microhardness line tracing, the average weld metal microhardness was observed to reach 285 HVN with a standard deviation of 14 HVN. By increasing the heat input to $509 \mathrm{~J} / \mathrm{mm}$, a significant decrease in the amount of lath martensite with an increase in grain boundary ferrite and ferrite with second phase was ob- 

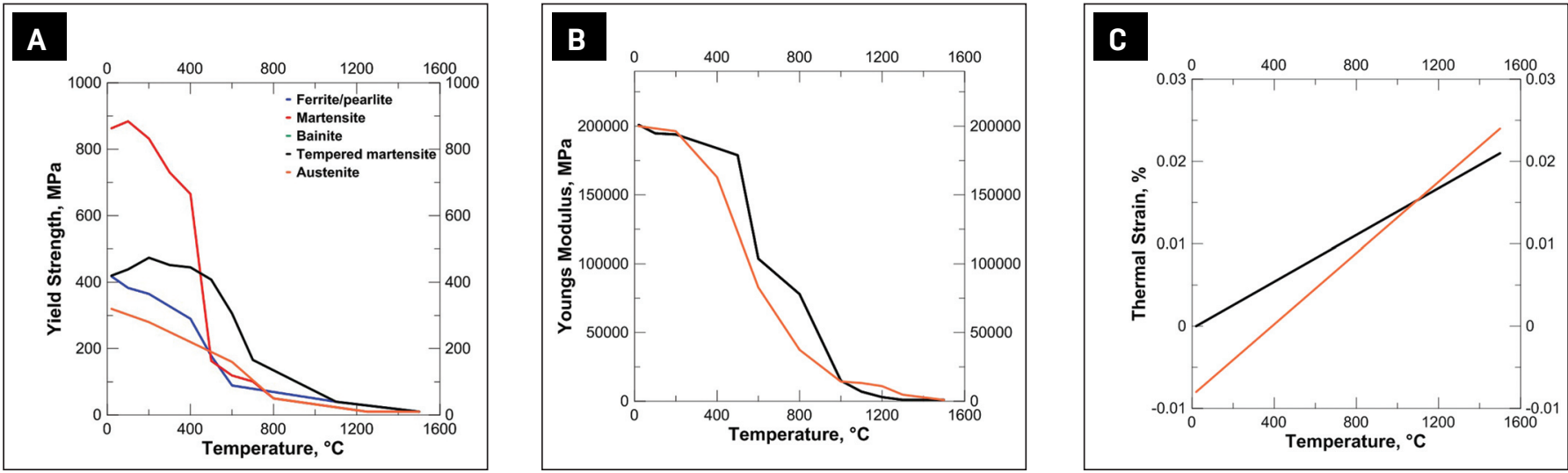

Fig. 5 - ASTM-516 Grade 70 Sysweld ${ }^{T M}$ material database: A - Yield strength; B - Young's modulus; C - thermal strain.
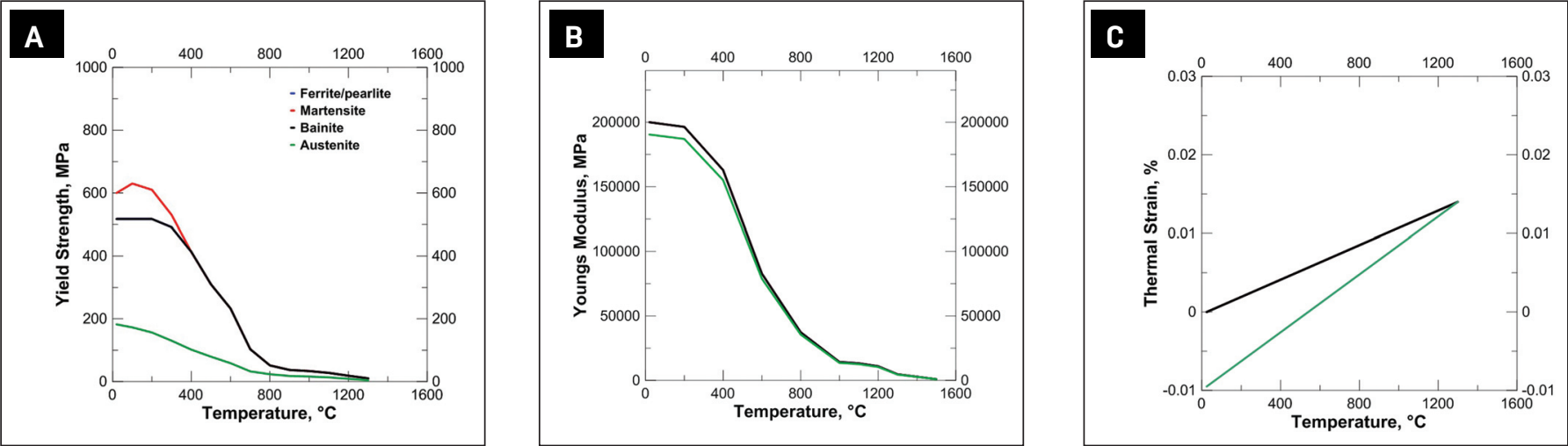

Fig. 6 - ER70S-6 Sysweld ${ }^{\mathrm{TM}}$ material database: $A$ - Yield strength; B - Young's modulus; $C$ - thermal strain.

served in Fig. 8B. The average weld metal micro-hardness decreased to $245 \mathrm{HVN}$ with a standard deviation of $9 \mathrm{HVN}$.

Under similar welding conditions, Glover et al. indicated a local lath martensite hardness of $390 \mathrm{HVN}$, whereas Onsøien et al. indicated a hardness range of 215-235 HVN for ferrite with second phase (Refs. 24, 25). This demonstrates an agreement is reached between phase identification and the microhardness results. At $327 \mathrm{~J} / \mathrm{mm}$ heat input, the average weld metal microhardness of $285 \mathrm{HVN}$ lays in the middle between martensite and ferrite with second phase respective microhardnesses indicating a dominant presence of both phases. At $509 \mathrm{~J} / \mathrm{mm}$ heat input, however, the $245 \mathrm{HVN}$ average microhardness is close to the reported ferrite with second phase microhardness range of 215-235 HVN, indicating a dominant presence of ferrite with second phase and a significant decrease of the lath martensite phase in the weld metal. Varied as a function of heat input, both the FEA and metallographic point counting phase amount results are illustrated in Fig. 9A-C for martensite, ferrite with second phase, and ferrite phases in the weld metal, respectively. The error bars represent the $95 \%$ point counting confidence interval calculated by following ASTM E562. Close trends of phase amounts were observed by both FEA modeling and metallographic point counting. A maximum deviation of $6 \%$ was observed in ferrite with second phase, at a heat input of $509 \mathrm{~J} / \mathrm{mm}$, indicating a general good agreement and validation of FEA phase amount computations.

At $6.3-\mathrm{mm}$ base plate thickness and $327 \mathrm{~J} / \mathrm{mm}$ heat input, the bottom surface FEA and hole-drilling strain gauge residual stress results are shown in Fig. 10A-D, following the transverse and longitudinal axes demonstrated in Fig. 7B. Close profiles were observed by both FEA and hole-drilling strain gauge experimental validation. The maximum deviation was observed at a 30-mm transverse distance, as shown in Fig. 10B, which reached $9 \%$ of the base plate yield strength. Such deviation was found to be within the ASTM E837, and Schajer (Refs. 23, 26) expected error margins that range from 5 to $20 \%$. The temperature and distortion validation results can be found in Part I of this study, which also showed good agreement with respective FEA modeling results (Ref. 17).

\section{Experimental Validation Discussion}

Through the experimental validation results obtained and analysis performed, a good agreement was consistently acquired. One key reasoning of the good agreement obtained was the use of a FEA modeling material database that had material properties quantified as a function of the transiently present metallurgical phase and transient temperature, ranging from room temperature to the melting point. In addition, the use of continuous cooling transformation and austenitization diagrams allowed for 

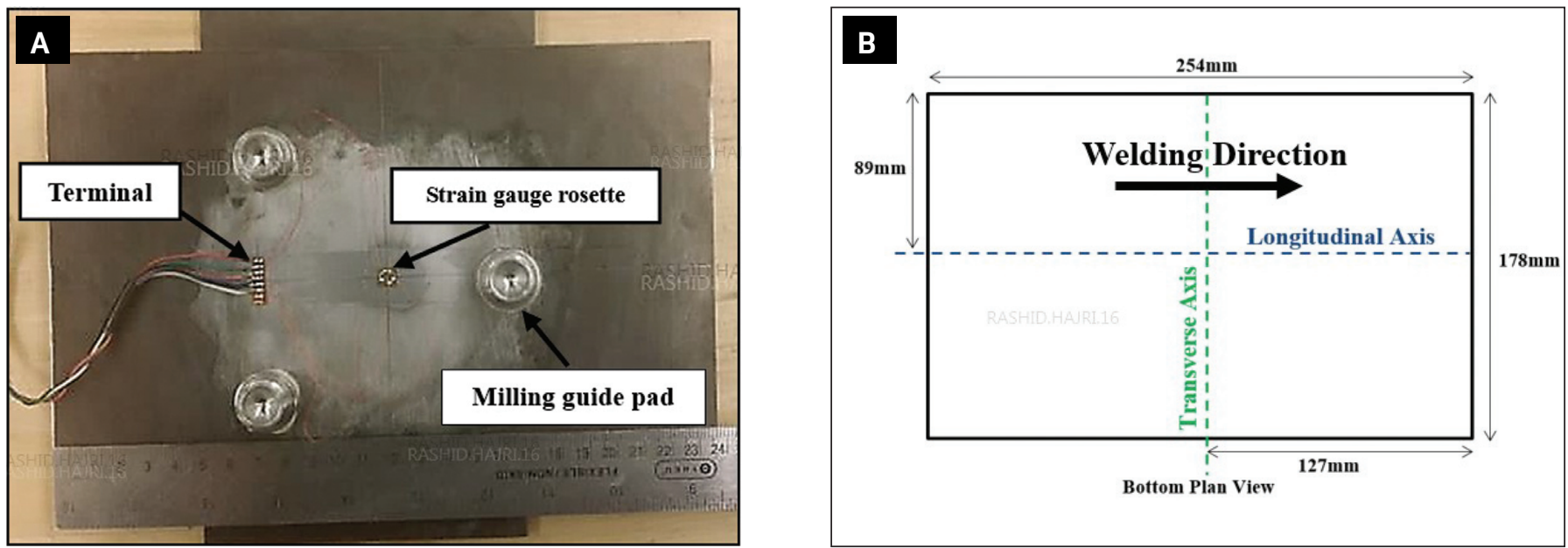

Fig. 7-A - Hole-drilling strain gauge residual stress measurement setup with the strain gauge rosette located at the bottom surface; $B$ - bottom surface schematic illustration with transverse and longitudinal axes superimposed.
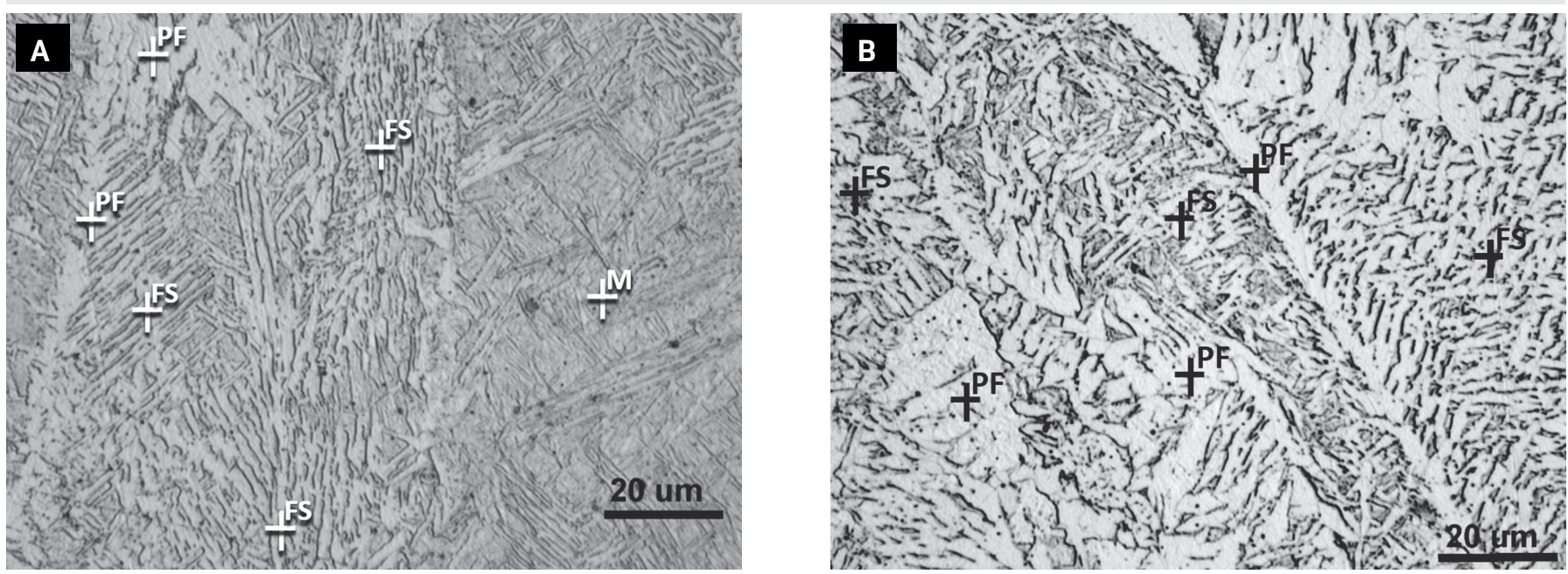

Fig. 8 - Optical micrographs of weld metal with heat input values and 6.3-mm-base plate thickness (M: martensite; FS: ferrite with second phase; PF: primary ferrite): $A-327 \mathrm{~J} / \mathrm{mm}$; $B-509 \mathrm{~J} / \mathrm{mm}$.

the consideration of phase transformation in the FEA computation. The experimental validation results with their small deviations indicated the FEA modeling and the material database used were satisfactory and can be used to study the effects of preheating and clamping.

\section{Finite-Element Analysis Modeling Results}

\section{Preheating Effect}

At $6.3 \mathrm{~mm}$ thickness and $327 \mathrm{~J} / \mathrm{mm}$ heat input, Fig. 11A and B represents the through-thickness residual stress distributions from weld top to bottom surface at both preheated and unpreheated welding conditions. The through-thickness distribution path followed the highlighted 3D elements in Fig. 12A, taken at the welding midpath cross-sectional plane, illustrated in Fig. 12B. Superimposed lines are included in Fig. 11A and B to represent the fusion zone and HAZ boundaries at both preheated and unpreheated conditions. This is to correlate the explanation of the residual stress distributions to each specific weldment local region in the through-thickness direction.

The HAZ depth was observed to increase by inducing a preheating treatment to the weldment. At $6.3 \mathrm{~mm}$ thickness and $327 \mathrm{~J} / \mathrm{mm}$ heat input, the HAZ depth distance was $1.4 \mathrm{~mm}$ at the unpreheated condition, which was increased to $1.7 \mathrm{~mm}$ with preheating at $95^{\circ} \mathrm{C}$. This represents $18 \%$ of HAZ depth increase. This observation can be explained by the inherent increase of the peak temperatures with imposing a preheating treatment to the weldment, compared to the unpreheated condition.

Looking into the through-thickness residual stress distribution at the unpreheated condition, the weld metal longitudinal residual stresses were observed to fall in a range from 376 to $400 \mathrm{MPa}$, while the transverse stresses ranged from -86 to $30 \mathrm{MPa}$. In the $\mathrm{HAZ}$ region, the lowest residual stresses were located in the coarse-grained HAZ (CGHAZ), where the local peak temperature exceeded $1100^{\circ} \mathrm{C}$. This behavior is attributed to the dominant martensite present in the CGHAZ by following the FEA modeling metallurgical computation. In the CGHAZ, the 

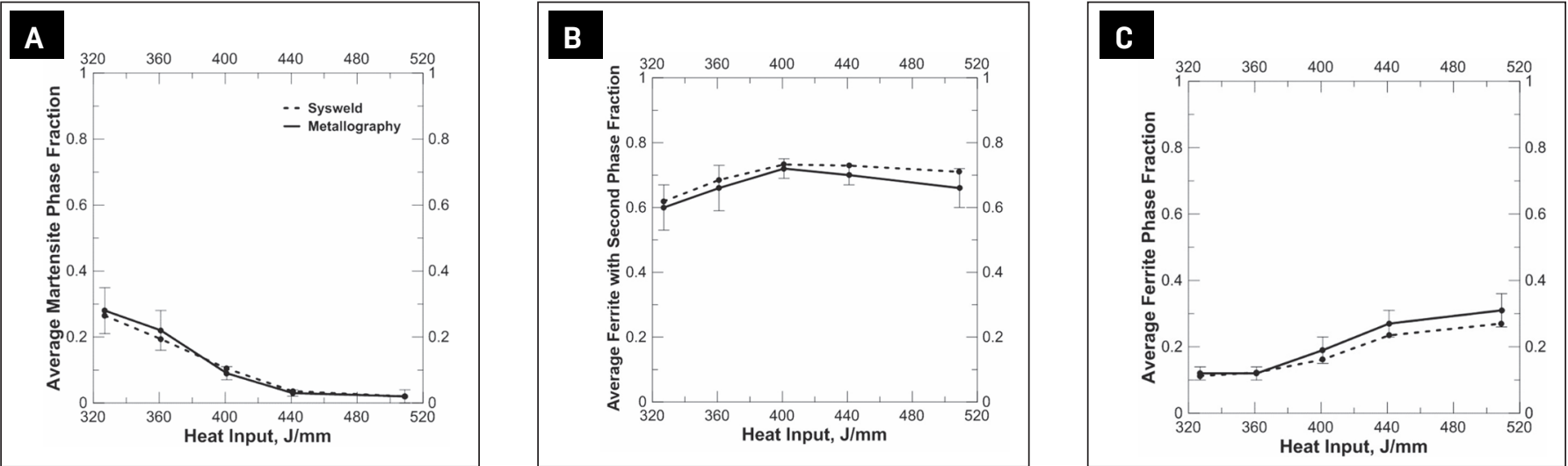

Fig. 9-A - Average FEA and metallography weld metal martensite B - ferrite with second phase; $C$ - ferrite phase fractions varied as a function of heat input (6.3- $\mathrm{mm}$ base plate thickness).

\section{A}

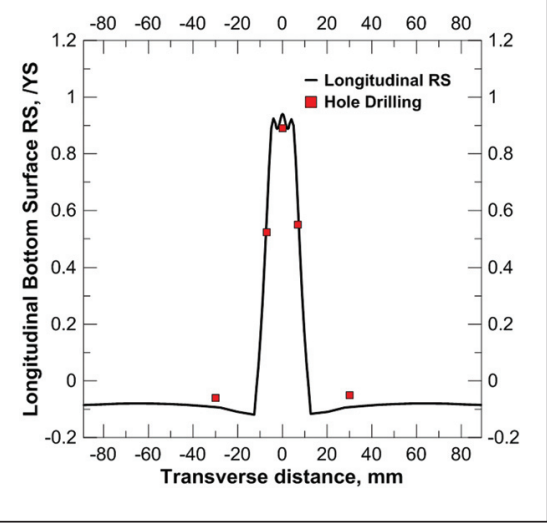

\section{C}

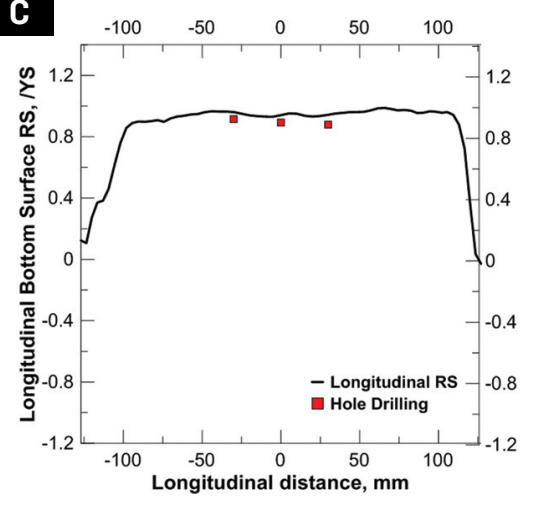

\section{B}

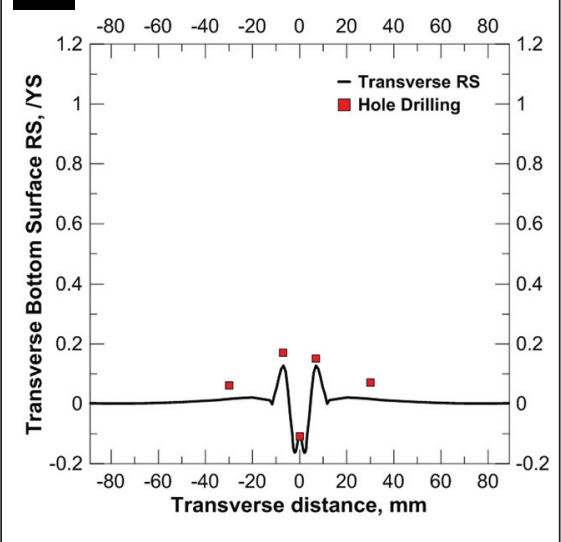

\section{D}

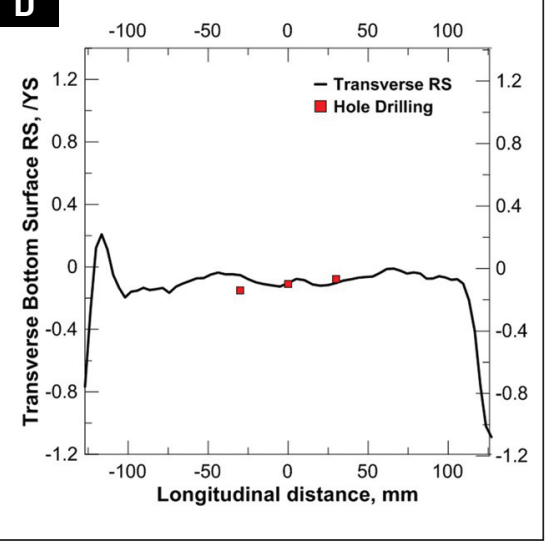

Fig. 10 - Measured (A), FEA longitudinal (C), and transverse (B and D) residual stress distributions along the transverse and longitudinal axes for $327 \mathrm{~J} / \mathrm{mm}$ heat input and 6.3-mm base plate thickness.

austenite started to transform to martensite at $420^{\circ} \mathrm{C}$, which locally induces compressive transformationinduced stresses. These led to residual stresses that are lowest at the CGHAZ when compared to other sub-HAZ regions. In the through-thickness direction, the peak residual stresses are consistently located at the HAZ

boundary where both intercritical and subcritical HAZ regions coexist. This behavior was attributed to the appreciable local thermal strains and the low transformation-induced strains experienced during the welding thermal cycle at such a region. By further increasing the distance from the weld top, the residual stresses were found to gradually decrease until the bottom surface was reached. The eventual increase in residual stresses prior to reaching the bottom surface was observed to be induced by mechanical equilibrium. By following the throughthickness direction, the local peak temperature decreased with increasing the distance from the weld metal fusion boundary. This, therefore, indicates that higher thermal strains exist within the base metal regions that are located at distances close to the HAZ boundary and lower thermal strains, and thereby stresses exist at increased distances from the HAZ boundary. Therefore, such an increase of residual stresses prior to reaching the bottom surface was not caused by the local thermal strains but induced by mechanical equilibrium. At the bottom surface, the peak residual stress without preheating was observed to reach $395 \mathrm{MPa}$, which represents $95 \%$ of the base metal yield strength.

Looking into the preheated welding condition, the weld metal longitudinal residual stresses were lowered by range of 5 to $15 \mathrm{MPa}$, compared to the unpreheated condition. However, the transverse residual stresses were increased by $83 \mathrm{MPa}$, at a maximum level. This increase can be attributed to the reduction of the weld metal martensite amount from 27 to $6 \%$, after preheating, following the FEA computations. In addition, the CGHAZ residual stresses were observed to be significantly lowered after preheating. After preheating, the longitudinal residual stresses at the CGHAZ were reduced by a range of 110 to $130 \mathrm{MPa}$ 
while the transverse stresses were reduced by a range of 20 to $35 \mathrm{MPa}$. At both preheated and unpreheated conditions, the CGHAZ was dominantly martensitic, according to the FEA computations. This leads to the conclusion that, upon preheating, the thermal strain reduction in conjunction with martensite transformationinduced compressive strains led to the significant local residual stress reduction in the CGHAZ. In the throughthickness direction, the peak residual stress value at the intercritical and subcritical HAZ was reduced by 55 $\mathrm{MPa}$ after preheating. This is attributed to the reduction of thermal strains, induced by preheating, compared to the unpreheated condition with no significant transformationinduced strains present at both intercritical and subcritical HAZ regions. The bottom surface longitudinal residual stress was found to be $377 \mathrm{MPa}$, $90 \%$ of base metal yield strength, after preheating, which is lower than the unpreheated condition by $5 \%$ of the base metal yield strength. Although the distance between the HAZ boundary and bottom surface was slightly reduced after preheating, which should
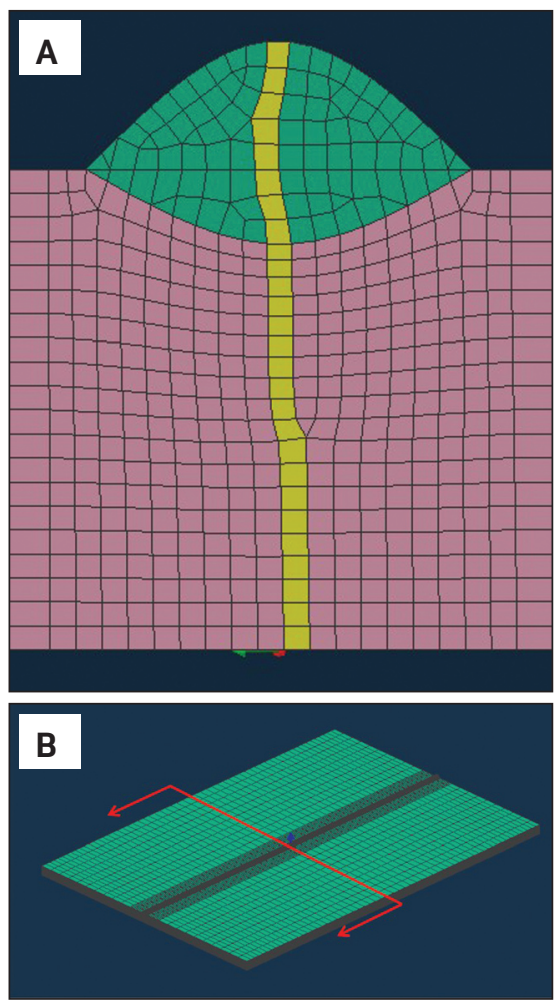

Fig. $12-3 D$ element: $A-$ Throughthickness path; B - mid-path crosssectional plane.

\section{A}

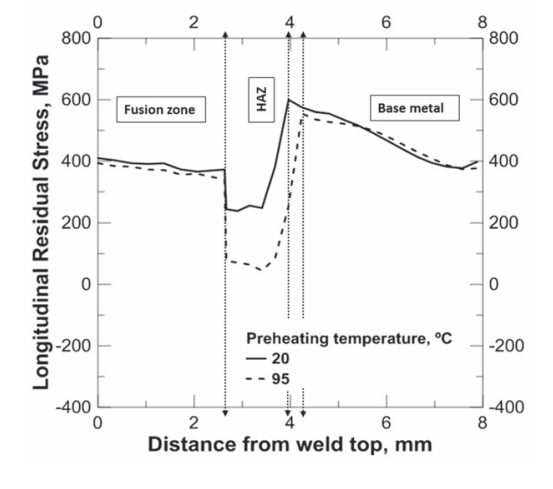

\section{B}

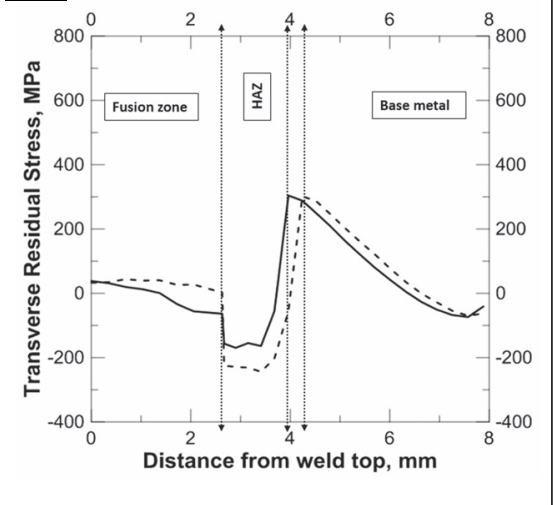

Fig. $11-$ Residual stress through-thickness distributions of $327 \mathrm{~J} / \mathrm{mm}$ and $6.35 \mathrm{~mm}$ thickness showing both unpreheated and preheated conditions: A - Longitudinal; B transverse.

tend to increase the bottom surface residual stresses), the bottom surface residual stresses were reduced. This can be attributed to the CGHAZ, intercritical, and subcritical HAZ local

Figure $13 \mathrm{~A}$ and $\mathrm{B}$ represents the corresponding through-thickness residual stress distributions at $19-\mathrm{mm}$ base plate thickness and $327 \mathrm{~J} / \mathrm{mm}$ heat input. Similarly, the HAZ depth distance was increased from 1.1 to 1.4 $\mathrm{mm}$, after a preheating treatment, which represents a $27 \%$ increase of the HAZ depth distance.

According to the FEA computations, the weld metal martensite amount, after preheating, is still significant, but was reduced by $30 \%$. This may explain the slight increase of weld metal transverse residual stresses, after preheating, due to the martensite amount reduction. The weld metal

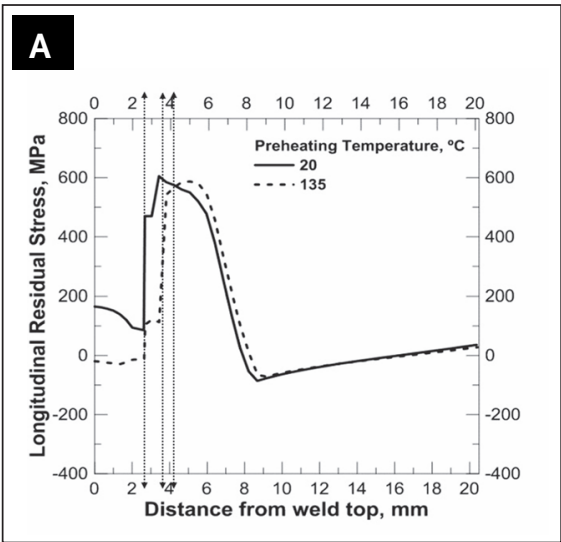
residual stress reduction.

longitudinal residual stresses, however, were significantly reduced after preheating, with a range of 100 to 180 MPa residual stress reduction. The CGHAZ is dominantly martensitic at both unpreheated and preheated conditions. Due to the reduction of thermal strains and insignificant changes in phase amounts, the residual stresses were quite significantly reduced at the CGHAZ. After preheating, the peak residual stresses at the intercritical and subcritical HAZ regions were reduced by $28 \mathrm{MPa}$. The bottom surface longitudinal residual stress was observed to be $28 \mathrm{MPa}, 7 \%$ of base metal yield strength, after preheating, which is lower than the unpreheated condition by $1 \%$ of yield strength. In addition, the bottom surface transverse residual stress, after preheating, was $88 \mathrm{MPa}, 21 \%$ of yield strength, which is lower than the unpreheated condi-

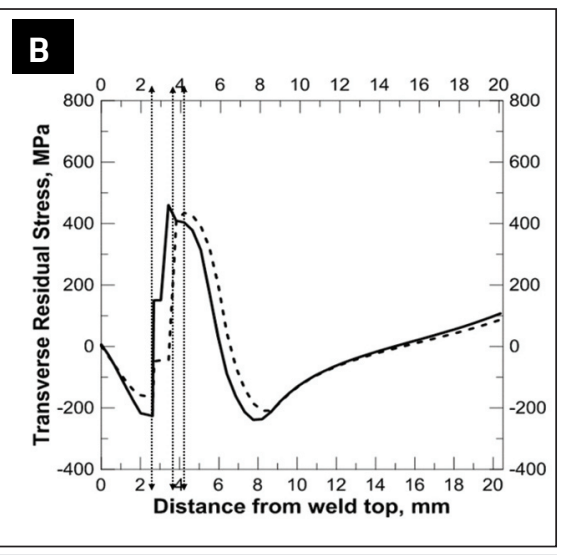

Fig. 13 - Residual stress through-thickness distributions of $327 \mathrm{~J} / \mathrm{mm}$ and $19 \mathrm{~mm}$ thickness showing both unpreheated and preheated conditions: A - Longitudinal; $B$ - transverse. 

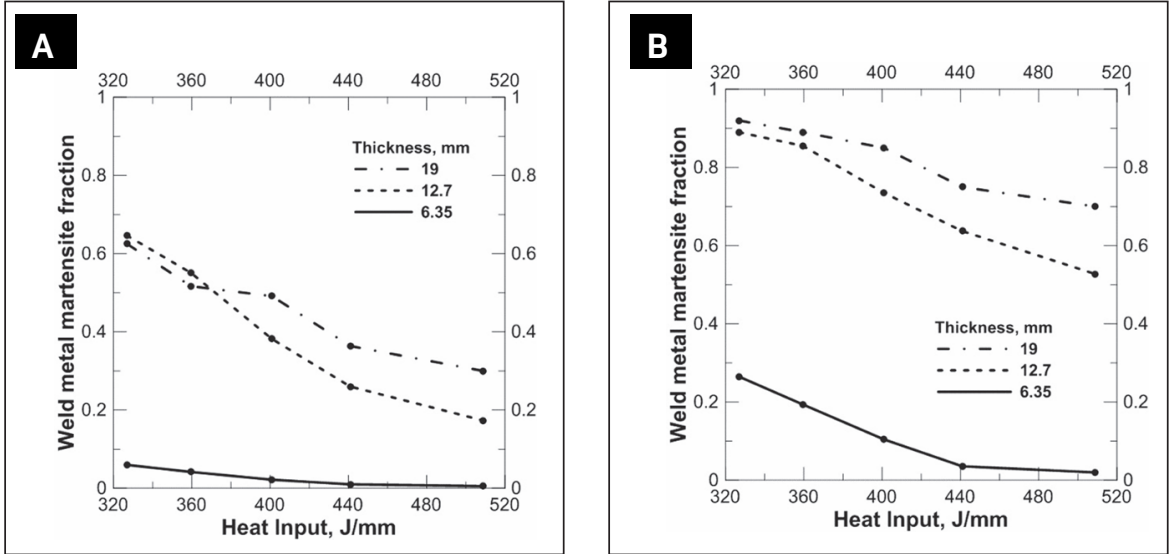

Fig. 14 - FEA weld metal martensite phase amounts varied as a function of the welding heat input and base plate thickness: $A$ - Preheated; $B$ - unpreheated welding condition.
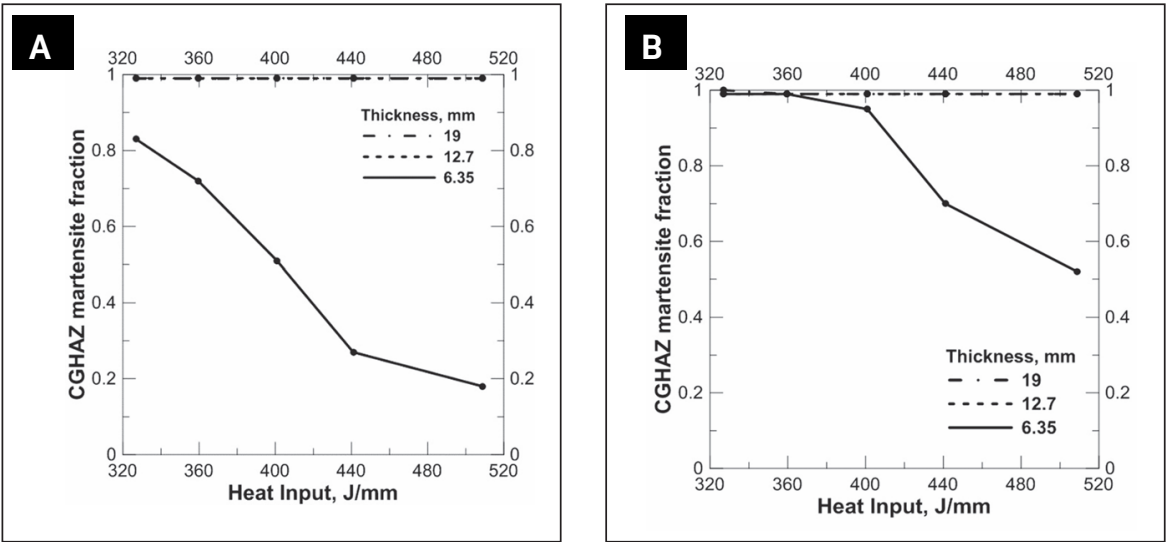

Fig. 15 - FEA CGHAZ martensite phase amounts varied as a function of welding heat input and base plate thickness: $A$ - Preheated; B - unpreheated welding conditions.
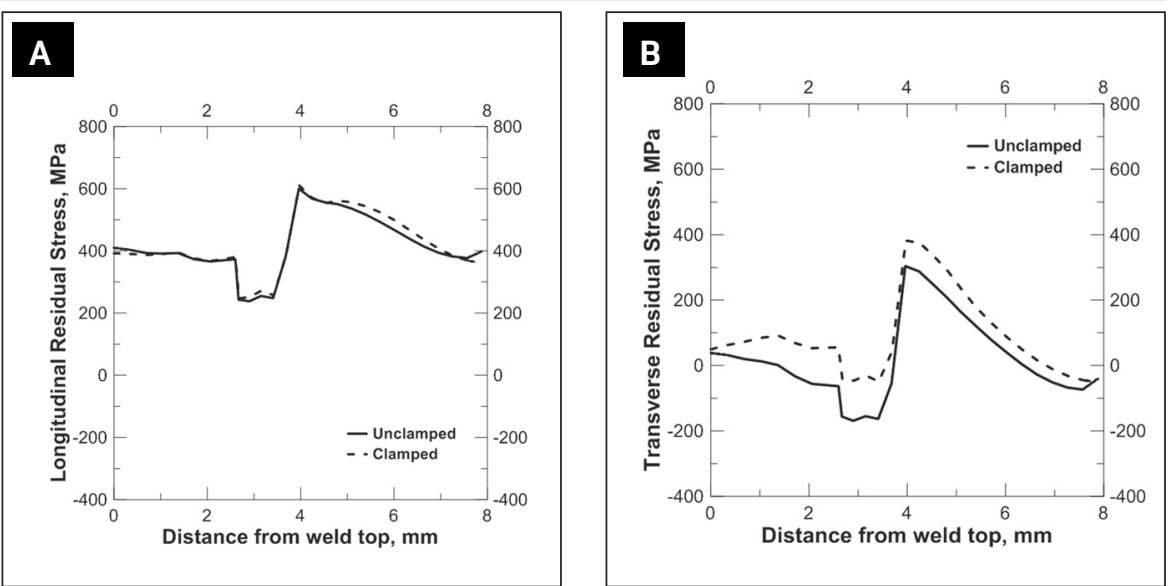

Fig. 16 - Residual stress through-thickness distributions of $327 \mathrm{~J} / \mathrm{mm}$ and $6.3 \mathrm{~mm}$ thickness illustrating both unclamped and clamped welding conditions: A - Longitudinal; $B$ - transverse.

tion by $5 \%$ of yield strength.

Figure $14 \mathrm{~A}$ and $\mathrm{B}$ illustrates the FEA computed weld metal martensite phase amounts varied as a function of welding heat input and base plate thickness, with and without preheating, respectively. Figure 15A and B illustrates the corresponding martensite phase amount results for the CGHAZ, with and without preheating, respectively.
Looking into Fig. 14B, the weld metal martensite amounts are reduced with increasing the heat input value, at all base plate thickness levels. In addition, the greater the base plate thickness, the greater the martensite phase amount is observed, which is attributed to the increase of the cooling sink volume with increasing the thickness level of the base plate. With introducing preheating (Fig. 14A), the martensite phase amounts are reduced uniformly at all heat input and base plate thickness values. The most significant decrease of weld metal martensite amount is observed at $19 \mathrm{~mm}$ thickness, while the least decrease is observed at $6.3 \mathrm{~mm}$. This behavior is attributed to the highest preheating temperature, $135^{\circ} \mathrm{C}$, introduced to the 19-mm thickness level while lowest temperature, $95^{\circ} \mathrm{C}$, was imposed to the $6.3 \mathrm{~mm}$ thickness.

Looking into Fig. 15B, the CGHAZ is found to be dominantly martensitic at all heat input values at the 12.7and 19-mm thickness levels. At 6.3mm thickness, the martensite amount was observed to be high at heat input values less than $440 \mathrm{~J} / \mathrm{mm}$ and decreased significantly with increasing heat input, reaching 52\%, at 509 $\mathrm{J} / \mathrm{mm}$ heat input. At the preheated condition, Fig. 15A, the martensite phase amount at the 6.3-mm thickness level were observed to be uniformly reduced while at 12.7 and 19 $\mathrm{mm}$ thickness levels martensite phase amounts were not found to be affected. In the CGHAZ, preheating effect was pronounced at the $6.3-\mathrm{mm}$ thickness level because of the smaller cooling sink volume in which the cooling rates can be more significantly reduced with a preheating treatment. At 12.7and 19-mm thicknesses, the cooling sink volume is large enough where the cooling rates at the CGHAZ are still greater than the martensite transformation critical cooling rate, with preheating.

\section{Rigid Clamping Effect}

At 6.3-mm thickness and 327 $\mathrm{J} / \mathrm{mm}$ heat input, Fig. 16A and B represents the corresponding throughthickness residual stress distributions at both clamped and unclamped welding conditions. Similarly, the distribution path followed the highlighted $3 \mathrm{D}$ elements in Fig. 11A. 
Looking into the clamped welding condition, clamping slightly increased the longitudinal residual stresses at the HAZ and base metal regions. The transverse residual stresses at the weld metal, HAZ, and base metal were, however, significantly increased. In addition, the peak transverse residual stress values at the intercritical and subcritical HAZ regions were also increased significantly. The significant transverse residual stress increase is attributed to the clamping configuration (Fig. 4B) in which the distortion displacement restriction was clearly pronounced in the transverse axis more than the longitudinal axis. Looking into the bottom surface, the residual stress rise prior to reaching the bottom surface was absent at the clamped condition. This can be attributed to the overall residual stress increase in the weld metal, HAZ, and base metal regions close to the HAZ boundary. This absence of a residual stress rise, which was induced by mechanical equilibrium, led to a decrease in bottom surface local residual stresses. The bottom surface longitudinal residual stress reached $359 \mathrm{MPa}$, after clamping, representing $85 \%$ of base metal yield strength, whereas the transverse stress reached $-52 \mathrm{MPa}$, $-12 \%$ of yield strength. This corresponds to a reduction of $10 \%$ of yield strength in the bottom surface longitudinal residual stress compared to unclamped welding condition.

At 6.3-mm thickness, such behavior of reducing the bottom surface residual stress, after clamping, was not manifested at higher heat input values where the residual stress rise prior to reaching the bottom was originally absent, at the unclamped condition. At such condition, clamping caused an overall increase of residual stresses in the through-thickness direction, including the local bottom surface region. Figure $17 \mathrm{~A}$ and $\mathrm{B}$ represents an example at $441 \mathrm{~J} / \mathrm{mm}$ heat input and 6.3-mm base plate thickness. At the clamped condition, the bottom surface longitudinal residual stress reached a value of $488 \mathrm{MPa}, 116 \%$ of yield strength, while the transverse stress reached $85 \mathrm{MPa}, 20 \%$ of yield strength. This corresponds to an increase of 20 and $36 \%$ of yield strength in the bottom surface longitudinal and transverse residual stresses, respec-
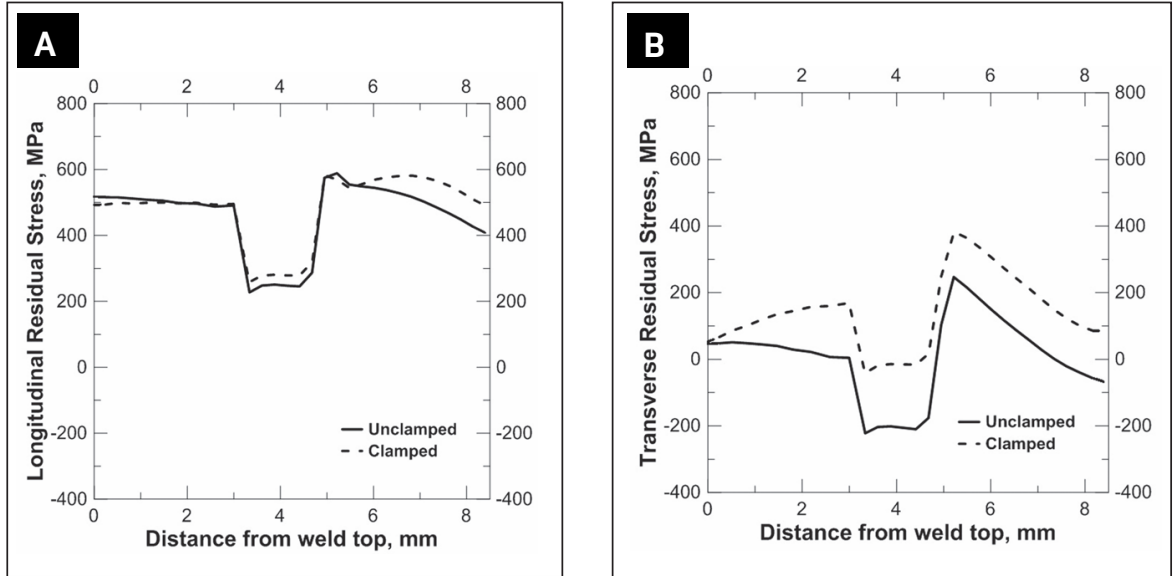

Fig. 17 - Residual stress through-thickness distributions of $441 \mathrm{~J} / \mathrm{mm}$ and $6.3 \mathrm{~mm}$ thickness illustrating both unclamped and clamped welding conditions: $A-$ Longitudinal; $B$ - transverse.

\section{A}

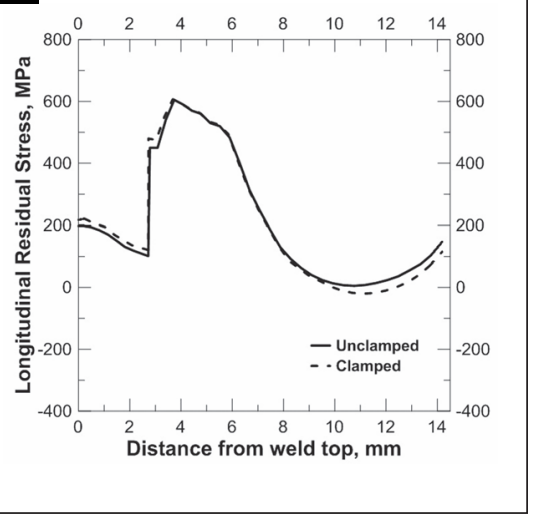

B

Fig. 18 - Residual stress through-thickness distributions of $327 \mathrm{~J} / \mathrm{mm}$ and $12.7 \mathrm{~mm}$ thickness illustrating both unclamped and clamped welding conditions: A - Longitudinal; $B$ - transverse.

\section{A}

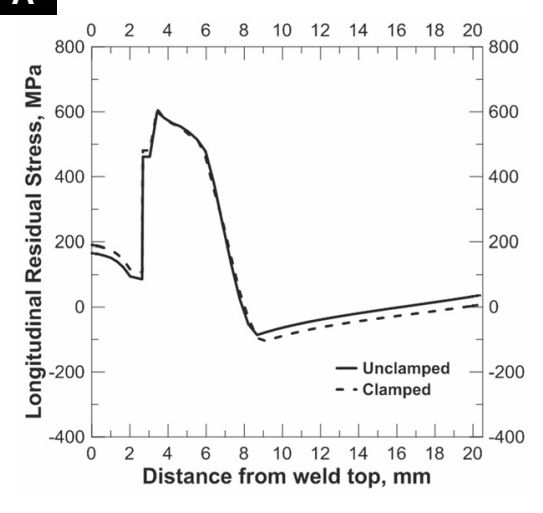

B

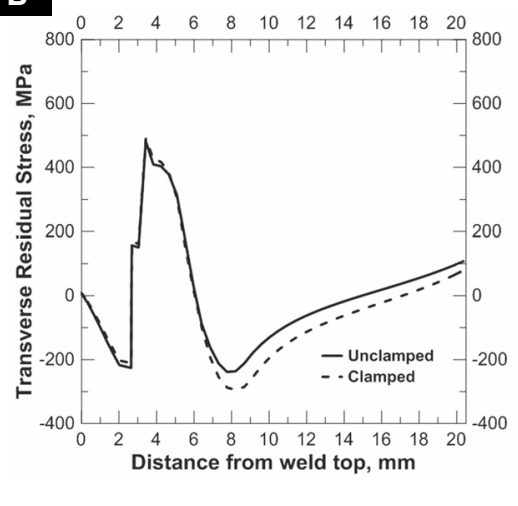

Fig. 19 - Residual stress through-thickness distributions of $327 \mathrm{~J} / \mathrm{mm}$ and $19 \mathrm{~mm}$ thickness illustrating both unclamped and clamped welding conditions: $A-$ Longitudinal; B - transverse.

tively, compared to the unclamped condition.

The corresponding longitudinal and transverse residual stress distributions at $12.7-\mathrm{mm}$ base plate thickness and $327 \mathrm{~J} / \mathrm{mm}$ are illustrated in Fig. 18A 

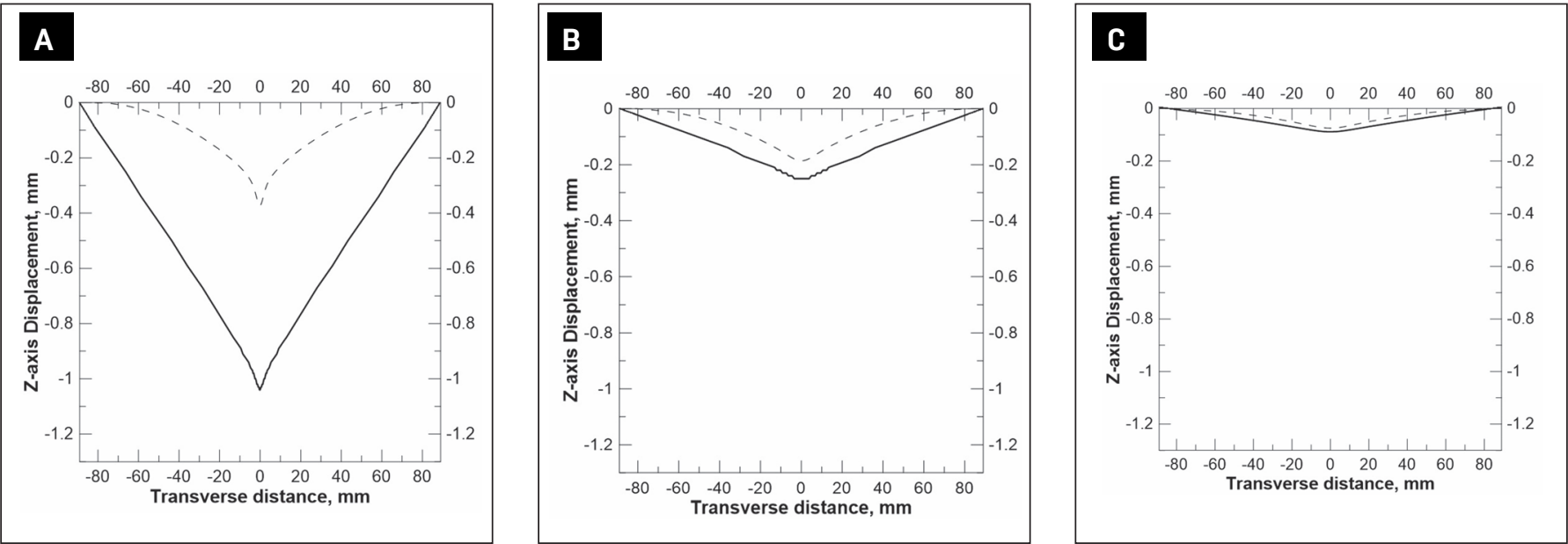

Fig. 20 - Distortion profiles following the transverse axis in Fig. 7B. Base plate thickness (unclamped: solid curve, clamped: dashed curve): $A-6.3 ; B-12.7 ; C-19 \mathrm{~mm}$.

\section{A}

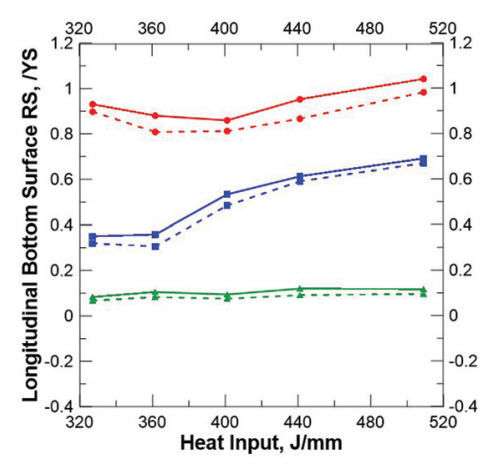

Fig. 21 - Effect of preheating on bottom surface longitudinal $(A)$ and transverse $(B)$ residual stresses as a function of heat input and base plate thickness (un-preheated: solid curve, preheated: dashed curve).

\section{A}

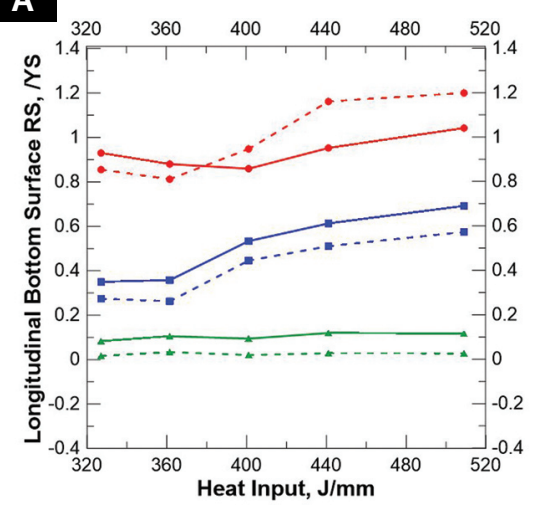

\section{B}

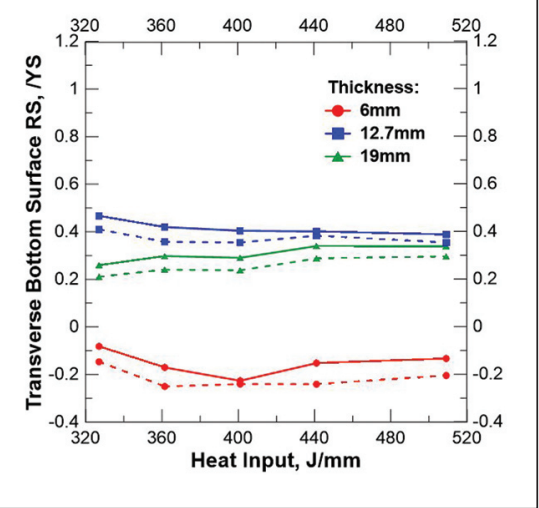

mm was significantly less pronounced. Such lower level of residual stress increase was attributed to the significantly lower distortion level that was originally present at $12.7-\mathrm{mm}$ base plate thickness, at the unclamped, compared to $6.3 \mathrm{~mm}$ thickness. Therefore, the distortion reduction by clamping at 12.7-mm was significantly lower than $6.3 \mathrm{~mm}$ thickness. Due to increased base plate thickness and thereby longer distance between the HAZ boundary and the bottom surface, the equilibrium induced residual stresses, close to the bottom surface, were slightly altered. Compared to the 6.3-mm thickness level, the changes in bottom surface residual stresses were not as significant. After clamping, the bottom surface longitudinal and transverse residual stresses reached 115 and $220 \mathrm{MPa}, 27$ and $52 \%$ of base metal yield strength, respectively. Compared to the unclamped condition, this results in a reduction of $8 \%$ of yield strength for the longitudinal residual stress, whereas transverse residual stress increased by $5 \%$ of yield strength.

Figure 19A and B illustrates the corresponding longitudinal and transverse residual stress distribution results at the 19-mm thickness level and $327 \mathrm{~J} / \mathrm{mm}$ heat input, respectively. Similar to the $12.7 \mathrm{~mm}$ thickness, clamping slightly increased both weld metal and HAZ longitudinal and transverse residual stresses. The increase of residual stresses was less pronounced than the $6.3 \mathrm{~mm}$ thickness. This is, similarly, attributed to the less distor-

and $\mathrm{B}$, respectively. Clamping caused a slight increase of both the weld metal and HAZ longitudinal and transverse residual stresses. However, compared to $6.3-\mathrm{mm}$ base metal thickness, the increase of residual stresses at 12.7

Fig. 22 - Effect of clamping on bottom surface longitudinal (A) and transverse (B) residual stresses as a function of heat input and base plate thickness (unclamped: solid curve, clamped: dashed curve). 
tion level and reduction at $19 \mathrm{~mm}$ thickness compared to $6.3 \mathrm{~mm}$. Due to the changes of residual stress values at the weld metal and HAZ, the mechanical equilibrium induced residual stresses at distances greater than 8 and $6 \mathrm{~mm}$ for longitudinal and transverse stresses, respectively, were slightly altered. At the clamped welding condition, the bottom surface longitudinal residual stress reached 7 $\mathrm{MPa}, 2 \%$ of yield strength, while the transverse residual stress reached 79 $\mathrm{MPa}, 19 \%$ of yield strength. This led to a reduction of $7 \%$ of yield strength in both longitudinal and transverse residual stresses, compared to the unclamped welding condition.

Figure 20A-C illustrates the distortion profiles of both clamped and unclamped conditions by following the transverse axis illustrated in Fig. 7B and at 6.3-, 12.7-, and 19-mm base plate thickness, respectively. Distortion displacements significantly increased with decreasing base plate thickness. In addition, the reduction of distortion displacements after clamping decreased with increasing base plate thickness. This explains the amount of weld metal and HAZ residual stress increase, which was lowest at $19 \mathrm{~mm}$ thickness and highest at 6.3 mm thickness.

\section{Finite-Element Analysis Modeling Discussion}

The effect of preheating on bottom surface longitudinal and transverse residual stresses is illustrated in Fig. $21 \mathrm{~A}$ and $\mathrm{B}$, respectively, as a function of both heat input and base plate thickness. The residual stress values are taken at the transverse and longitudinal axes cross section, in Fig. 7B, which represents the weldment thermal and residual stress steady state region. The bottom surface residual stresses consistently decreased with inducing a preheating treatment at all heat input values and base plate thicknesses. The reduction of residual stresses at the bottom surface is attributed to the reduction of the thermal strains and, thereby, thermal residual stresses in the weld metal, $\mathrm{HAZ}$, and base metal regions that experienced high peak temperatures. However, the reduction of bottom sur- face residual stresses was insignificant and ranged from 2 to $8 \%$ of base metal yield strength only.

Corresponding to Fig. 21, Fig. 22A and $B$ represents the effect of clamping on the bottom surface longitudinal and transverse residual stresses, respectively, as a function of both heat input and base plate thickness. At 6.3$\mathrm{mm}$ base plate thickness and heat input equal and lower than $367 \mathrm{~J} / \mathrm{mm}$, the bottom surface longitudinal residual stresses were reduced after clamping. This reduction is attributed to the absence of the mechanical equilibrium induced residual stress rise prior to reaching the bottom surface, after clamping, as shown in Fig. 16A. At a heat input greater than $367 \mathrm{~J} / \mathrm{mm}$, the residual stresses were significantly increased due to clamping. At such heat input range, no mechanical equilibrium induced residual stress rise was observed originally at the unclamped condition. At the 12.7-mm thickness level, the bottom surface longitudinal stresses were reduced, while transverse residual stresses were increased, after clamping. At 19-mm base plate thickness, however, both longitudinal and transverse bottom surface residual stresses were slightly reduced. The bottom surface residual stress changes, at the 12.7- and 19-mm thickness levels, were slightly altered to encounter the slight increase in weld metal and HAZ residual stresses after clamping.

With preheating and clamping conditions and following the throughthickness direction, the peak residual stresses were consistently observed at the intercritical and subcritical HAZ region. This behavior was similarly observed at the unclamped and unpreheated condition and is attributed to local high thermal strains and low transformation induced strains present at such local regions.

From both Figs. 21 and 22, it can be observed that increasing the heat input increases the peak residual stresses reached at the bottom surface, irrespective of clamping and preheating imposition. In addition, Figs. 21 and 22 indicate that the base plate thickness is observed to constitute the most significant factor in the peak residual stresses reached at the bottom surface. This can be observed by comparing the bottom surface residual stresses at $6.3 \mathrm{~mm}$ thickness with 19 $\mathrm{mm}$ thickness level. At $6.3 \mathrm{~mm}$ base plate thickness, the bottom surface peak residual stresses exceeded $80 \%$ of the yield strength, with and without preheating and clamping. At $19 \mathrm{~mm}$ thickness, however, the residual stresses were lower than $35 \%$ of the yield strength, with and without clamping and preheating.

Clamping and preheating did not result in significant changes to the peak residual stresses reached at the bottom surface, at all heat input and base plate thickness, except at 6.3-mm base plate thickness and heat input values greater than $400 \mathrm{~J} / \mathrm{mm}$. At 6.3$\mathrm{mm}$ thickness level and heat input greater than $400 \mathrm{~J} / \mathrm{mm}$, clamping increased the bottom surface peak residual stress by a range from 22 to $35 \%$ of base plate yield strength, which constitutes the highest increase of bottom surface residual stresses.

Both clamping and preheating did not generally affect the conclusions of Part I of this study. According to NACE SP0472, paragraph 3.6.1, it is required to perform PWHT when tensile residual stresses exist in the entire through-thickness direction (Ref. 31). According to this criterion, external single-pass attachment welds at 6.3and $12.7-\mathrm{mm}$ thickness levels were found to require PWHT because of the through-thickness propagation of tensile residual stresses, by following the welding conditions followed in this study. At 19-mm thickness level, however, both compressive and tensile residual stresses coexisted in the through-thickness direction. This places an ambiguity whether the 19mm thickness level would require a PWHT. In addition to the residual stress extension behavior, it would be better if the NACE SP0472 criterion relied on the amount of residual stresses evolved at the bottom surface.

In the 6.3-mm thickness application and following the welding conditions of the study, the peak residual stresses at the bottom surface were found to exceed $80 \%$ of the base metal yield strength, with and without clamping and preheating. Such high residual stress exceeds the usual SCC threshold stress levels identified by Jones et al. (Ref. 27), which usually reaches $80 \%$ of yield strength. Hence, at 6.3-mm base plate thickness, PWHT 
is deemed necessary to avoid SCC at a heat input value within or higher than the range studied here. At the 12.7$\mathrm{mm}$ base plate thickness, a peak residual stress range of 36 to $69 \%$ of yield strength existed at the bottom surface, with and without preheating and clamping.

At such a base plate thickness level, the PWHT demand can be determined as a function of the specific SCC environment threshold stress as well as the design loading conditions. At the 19-mm thickness level, however, the peak residual stress reached a range from 19 to $35 \%$ only at the bottom surface, with and without clamping and preheating. At such residual stress levels, the risk of SCC is significantly lower. At the 19-mm or greater thickness level, the PWHT requirement can be considered optional or be waived, provided residual and design loading stresses are found not to exceed the SCC threshold stress. According to API 579-1/ASME FFS-1 Annex 9D, Fitness for Service (Ref. 28), a weld metal and HAZ residual stress of 20 to $30 \%$ of yield strength can be estimated to remain after a PWHT. This range of residual stress is quite close to that obtained at the 19-mm thickness level, which indicates that the PWHT demand at $19 \mathrm{~mm}$ thickness is significantly low.

\section{Conclusions}

Generally, preheating was found beneficial in reducing the residual stresses in the through-thickness direction. A residual stress reduction range from 2 to $8 \%$ of base metal yield strength existed at the bottom surface at the preheated condition.

Clamping was found to increase the residual stresses at the weld metal and $\mathrm{HAZ}$ at all heat input values and base plate thicknesses studied. Its effect on the bottom surface peak residual stress was insignificant, however, except at $6.3 \mathrm{~mm}$ thickness and a heat input value greater than $400 \mathrm{~J} / \mathrm{mm}$ where the peak stresses increased by a range from 22 to $35 \%$ of yield strength.

Among other welding conditions, the base plate thickness level constituted the most significant factor on the peak residual stress amount reached at the bottom surface, irre- spective of clamping and preheating. In addition, in the through-thickness direction, the peak residual stresses were invariably observed at the intercritical and subcritical HAZ regions.

With and without clamping and preheating, tensile longitudinal residual stresses existed in the throughthickness direction at $6.3-\mathrm{mm}$ and 12.7-mm base plate thickness. Both tensile and compressive stresses existed at $19 \mathrm{~mm}$ thickness. According to the NACE SP0472 criterion, PWHT is required for 6.3 and $12.7 \mathrm{~mm}$ thicknesses. The PWHT requirement does not explicitly apply for 19-mm-thick plates, however. It is suggested that such criterion should consider the amount of residual stresses reached at the bottom surface in addition to residual stress extension behavior in the through-thickness direction.

At the 6.3-mm thickness level, the bottom surface peak residual stresses reached and exceeded $80 \%$ of the base metal yield strength, with and without clamping and preheating. At such thickness level, PWHT is necessary to avoid SCC. At the 12.7-mm thickness level, the peak residual stresses at the bottom surface were found to range from 36 and $69 \%$ of the base metal yield strength, with and without clamping and preheating. At such thickness level, the PWHT should be required as a function of the SCC threshold stress and the design loading conditions. At the 19-mm thickness level, however, the peak stresses reached a range of 19 to $35 \%$ of base metal yield strength only. At this low stress level, PWHT can be potentially waived or optional depending on loading conditions.

\section{References}

1. Javadi, Y., Hasani, M., and Sadeghi, S. 2015. Investigation of clamping on the welding sub-surface residual stress and deformation by using the ultrasonic stress measurement and finite element method. Journal of Nondestructive Evaluation 34(1): 3. DOI: 10.1007/s10921-015-0277-9.

2. Casavola, C., Cazzato, A., Moramarco, V., and Pappalettere, C. 2015. Influence of the clamps configuration on residual stresses field in friction stir welding process. The Journal of Strain Analysis for Engineering Design 50(4): 232-242. DOI: $10.1177 / 0309324715573361$.
3. Aalami-Aleagha, M. E., and Eslampanah, A. H. 2012. Mechanical constraint effect on residual stress and distortion in T-fillet welds by three-dimensional finite element analysis. Proceedings of the Institution of Mechanical Engineers, Part B: Journal of Engineering Manufacture 227(2): 315-323. DOI: 10.1177/0954405412466 781

4. Reemsnyder, H. S., and Throop, J. F. 1982. Residual Stress Effects in Fatigue. American Society for Testing and Materials: Philadelphia, Pa. DOI: 10.1520/ STP776-EB.

5. Aalami-Aleagha, M. E., Foroutan, M. M., Feli, S. and Nikabadi, S. 2014. Analysis preheat effect on thermal cycle and residual stress in a welded connection by FE simulation. International Journal of Pressure Vessels and Piping, 114-115: 69-75. DOI: 10.1016/j.ijpvp.2013.12.003.

6. Teng, T.-L., and Lin, C.-C. 1998. Effect of welding conditions on residual stresses due to butt welds. International Journal of Pressure Vessel and Piping 75: 857-864. DOI: 10.1016/S03080161(98)00084-2.

7. Adedayo, S. M., and Adeyemi, M. B. 2000. Effect of preheat on residual stress distributions in arc-welded mild steel plates. Journal of Materials Engineering and Performance 9: 7-11. DOI: 10.1361/ 105994900770346213.

8. Totten, G., Howes, M., and Inoue, T. 2002. Handbook of Residual Stress and Deformation of Steel. ASM International: Materials Park, Ohio: pp. 391-397.

9. Leggatt, R. H. 2008. Residual stresses in welded structures. International Journal of Pressure Vessel and Piping 85: 144-151. DOI: 10.1016/j.ijpvp.2007. 10.004 .

10. Radaj, D. 1992. Heat Effects of Welding. Springer-Verlag Berlin Heidelberg: pp. 5-17.

11. Cheng, X., Fisher, J. W., and Prask, H. J. 2003. Residual stress modification by post-weld treatment and its beneficial effect on fatigue strength of welded structures. International Journal of Fatigue 25(9-11): 1259-1269. DOI: 10.1016/ j.ijfatigue.2003.08.020.

12. Dong, P., Song, S., and Zhang, J. 2014. Analysis of residual stress relief mechanisms in post-weld heat treatment. International Journal of Pressure Vessel and Piping 122: 6-14.

13. Suominen, L., Khurshid, M., and Parantainen, J. 2013. Residual stesses in welded components following post-weld treatment methods. Procedia Engineering 66: 181-191. DOI: 10.1016/j.proeng.2013. 12.073.

14. Adeyemi, M. B., Stark, R. A., and Modlen, G. F. 1980. Proceeding of heat treatment '79. Metals Society: 122-125.

15. Molzen, M. S., and Hornbach, D. 2001. Shot peening and heat treatment re- 
duce stress. Welding Journal 80(1): 38-42.

16. Alhajri, R., and Liu, S. 2016. Prediction of Residual Stresses Distribution in External Attachment Welding Applications to Evaluate the Need of PWHT. Proceeding on the $10^{\text {th }}$ International Conference on Trends in Welding Research, Tokyo, Japan.

17. Alhajri, R., Liu, S., Yu, Z., and Andreassen, M. J. 2017. Quantification of residual stresses in external attachment welding applications, Part I. Welding Journal 96(12): 451-s to 466-s.

18. Yurioka, N., and Kasuya, T. 1995. A chart method to determine necessary preheat temperature in steel welding. Quarterly Journal of Japan Welding Society 13(3): 347-357. DOI: 10.2207/qjjws.13.347.

19. ASTM International. 2011. ASTM E562-11, Standard Test Method for Determining Volume Fraction by Systematic Manual Point Count. West Conshohocken, Pa.

20. International Institute of Welding. 1988. Guide to the light microscope examination of ferritic steel weld metals. IIW Doc. IX-1533-88.

21. International Institute of Welding.
1983. Classification of microstructures in low C-low alloy steel weld metal and terminology. IIW Doc. IX-1282-83.

22. Thewlis, G. 2004. Classification and quantification of microstructures in steels: Material perspective. Materials Science and Technology 20: 143-160. DOI: 10.1179/ 026708304225010325.

23. ASTM International. 2013. ASTM E837-13a, Standard Test Method for Determining Residual Stress by the Hole-Drilling Strain-Gauge Method. West Conshohocken, Pa. DOI: 10.1520/E0837.

24. Glover, A. G., McGrath, J. T., Tinkler, M. J., and Weatherly, G. C. 1977. The influence of cooling rate and composition on weld metal microstructures in a $\mathrm{C} / \mathrm{Mn}$ and a HSLA steel. Welding Journal 56(9): 267-s to 273-s.

25. Onsøien, M. I., Liu. S., and Olson, D. L. 1996. Shielding gas oxygen equivalent in weld metal microstructure optimization Welding Journal 75(7): 216-s to 224-s.

26. Schajer, G., and Ruud, C. 2013. Practical Residual Stress Measurement Methods. Wiley Publication: New Jersey: pp. 1-27.
DOI: $10.1002 / 9781118402832$

27. Jones, R., and Ricker, R. 1992. Stress-Corrosion Cracking: Material Performance and Evaluation. ASM International: Metal Park, Ohio: pp. 1-38.

28. American Petroleum Institute American Society of Mechanical Engineers. 2016. API 579-1/ASME FFS-1: Fitness-ForService.

29. Chang, P., and Teng, T. 2004. Numerical and experimental investigation on the residual stresses of the butt-welded joints. Computational Materials Science 29(4): 511-522. DOI: 10.1016/ j.commatsci.2003.12.005.

30. AWS A9.5.2013, Guide for Verification and Validation in Computation Weld Mechanics. 2013. Miami, Fla.: American Welding Society.

31. NACE International. 2015. SP0472, Methods and Controls to Prevent In-Service Environmental Cracking of Carbon Steel Weldments in Corrosive Petroleum Refining Environments. Tex.

RASHED ALHAJRI (rashed.dh58@gmail.com) and STEPHEN LIU (sliu@mines.edu) are with the Colorado School of Mines, Center for Welding, Joining and Coatings Research, Golden, Colorado.

\section{Authors: Submit Research Papers Online}

Peer review of research papers is now managed through an online system using Editorial Manager software. Papers can be submitted into the system directly from the Welding Journal page on the AWS website (aws.org) by clicking on "submit papers." You can also access the new site directly at editorialmanager.com/wj/. Follow the instructions to register or log in. This online system streamlines the review process, and makes it easier to submit papers and track their progress. By publishing in the Welding Journal, more than 70,000 members will receive the results of your research.

Additionally, your full paper is posted on the American Welding Society website for FREE access around the globe. There are no page charges, and articles are published in full color. By far, the most people, at the least cost, will recognize your research when you publish in the world-respected Welding Journal. 